\title{
Emotionality, emotion regulation, and preschoolers' social adaptation*
}

\author{
KENNETH H. RUBIN, ${ }^{a}$ ROBERT J. COPLAN, ${ }^{a}$ NATHAN A. FOX, \\ AND SUSAN D. CALKINSb \\ ${ }^{a}$ University of Waterloo; and ${ }^{\circ}$ University of Maryland \\ Abstract \\ It was proposed that the interaction between the constructs of emotion regulation and social interaction would \\ predict social adaptation in preschoolers. Ninety-six 4-year-olds were observed in quartets of unfamiliar \\ same-sex peers. Based on parent temperament ratings and observed free play behaviors, 68 children from the \\ original sample were classified as: low social interaction, good emotion regulators; low social interaction, poor \\ emotion regulators; high social interaction, good emotion regulators; high social interaction, poor emotion \\ regulators; or average. The results indicated that the low social interaction children who were poor regulators \\ displayed more wary and anxious behaviors during free play and other episodes, and were rated as having \\ more internalizing problems than both the low social interaction children who were good regulators and the \\ average group. The high social interaction children who were poor regulators were rated as having more \\ externalizing problems than either the high social interaction children who were good regulators or the average \\ group. Thus, it seems as if emotion dysregulation is associated with psychological maladaptation, but that this \\ association is tempered by the degree to which children engage in social interaction.
}

Recent years have witnessed a burgeoning of interest in the study of emotions, their onset, their frequency and intensity of expression, and their regulation (e.g., Dodge, 1989; Thompson, 1990). This attention stems, in part, from the recognition that the dynamics of emotional experience, expression and regulation can influence the quality of children's social interactions and relationships (see Garber \& Dodge, 1991 for relevant reviews).

The significance of emotional dynamics for the study of social interaction and relationships has at least three sources. First, researchers have long recognized the functional importance of emotional displays for the transmission of information during social interaction (Campos, Campos, \& Barrett, 1989). Emotions are seen as regulating interaction as they themselves may be regulated or modulated (Thompson, 1990, 1994). For example, anger may be expressed functionally as a response to a frustrating situation; wariness may be expressed functionally as a response to a novel situation. In both cases, the expression of affect serves to alert members of the immediate social milieu that the child is being overwhelmed emotionally and that his or her behavior may be out of control. Thus, for caregivers, the expression of anger or wariness serves

\footnotetext{
* This research was supported by a grant from the National Institutes of Health to Nathan A. Fox (HD 17899) and by a grant from the John D. and Catherine T. MacArthur Foundation's Network on the Transition from Infancy to Childhood to Kenneth H. Rubin and Nathan A. Fox. The authors acknowledge Timothy R. Marshall, Jill Mankowitz, and Rebecca Lloyd (Maryland) for their help in data collection and David Lynch, Amy J. Rubin, and Shannon Stewart (Waterloo) for their help in coding the behavioral data.

Address correspondence and reprint requests to: Kenneth $\mathrm{H}$. Rubin, Department of Psychology, University of Waterloo, Waterloo, Ontario, Canada N2L 3G1.
}

Rubin, K.H., Coplan, R.J., Fox, N.A. \& Calkins, S.D. (1995). Emotionality, emotion regulation and preschooler's social adaptation. Development and Psychopathology, 7, 49-62.

Made available courtesy of Cambridge University Press 
functionally to indicate that some form of external regulation is called for. Both anger and wariness may be modulated or regulated in response to changes in situation or context. From this perspective, the study of emotional development is not simply focused on the emergence of emotional expression, but also on how emotions are regulated and how the process of emotion regulation facilitates social interaction (Calkins \& Fox, 1992; Dodge, 1991).

A second source for the study of emotions and their regulation stems from the literature on the development of socially maladaptive behaviors. For some time, researchers have discussed the expression of maladaptive behavior in terms of emotional dysregulation (e.g., Cole, Michel, \& O'Donnell, 1994). Children exhibiting aggressive behavior or problems of behavioral undercontrol (externalizing problems) have been viewed as having difficulties in the regulation of affect (Dodge, 1991). Similarly, a number of researchers have discussed patterns of behavioral overcontrol (internalizing problems) in the context of dysregulative emotion modulation (Garber, Braafladt, \& Zeman, 1991; Rubin \& Mills, 1991; Rubin, Stewart, \& Coplan, in press). Additionally, behavior in the classic Strange Situation paradigm has been discussed as reflecting either appropriate regulative or inappropriate dysregulative responses corresponding to secure or insecure attachment classifications (Belsky \& Rovine, 1987; Thompson, 1990). Thus, there has been a common concern among researchers vis-a-vis the manner in which emotion dysregulation arises and the roles played by emotion regulation in the development of dysfunctional social relationships and maladaptive social behaviors.

A third source of interest in emotions and their regulation is drawn from the study of infant and child temperament. To a large extent, researchers view emotional dynamics as underscoring temperamental dispositions; indeed, temperament has been defined as "characteristic individual differences in the intensive and temporal parameters of expression of emotionality and arousal" (Campos et al., 1989, p. 399).

Researchers who study temperament in children report that individuals differ not only in the ease with which positive and negative emotions may be aroused (emotionality, Buss \& Plomin, 1984; Derryberry \& Rothbart, 1984), but also in the ease with which emotions, once aroused, can be regulated (Rothbart \& Derryberry, 1981). Thus, following from the definition of temperament noted above, it has been argued that emotionality and affect regulation serve as the constitutional basis for temperament and personality in childhood (Derryberry \& Rothbart, 1984).

Reactivity is generally construed as representative of individual differences in threshold and intensity of emotional experience. It refers to responses to environmental stimuli that may be observed at the behavioral level in terms of motor and affective activity, or at the biological level in terms of autonomic and endocrine changes (Rothbart \& Derryberry, 1981). Regulation, on the other hand, is traditionally reflected by attentional, approach/ avoidance, and inhibitory mechanisms (Thompson, 1990). Thus, regulation refers to mechanisms that operate to control or modulate reactivity, and include such phenomena as changes in attention, behavioral approach or avoidance, and efforts at self-soothing. Regulatory processes begin to operate quite early in infancy, and through interactions with parents, develop into more complex mechanisms that allow the child to cope with emotional arousal with the assistance of parents. These regulatory processes eventually become critical to successful familial and extrafamilial interpersonal functioning (Cole et al., 1994; Garber \& Dodge, 1991).

These two dimensions of temperament, emotional reactivity and regulation, are dynamic processes that interact to produce patterns of behavior that become integral to the child's developing personality (Rothbart, 1988). Although considerable work has been conducted on behavioral and

Rubin, K.H., Coplan, R.J., Fox, N.A. \& Calkins, S.D. (1995). Emotionality, emotion regulation and preschooler's social adaptation. Development and Psychopathology, 7, 49-62.

Made available courtesy of Cambridge University Press 
physiological reactivity during infancy (Porges, 1991; Stifter \& Fox, 1990), and several researchers have examined the emergence of self-regulation during early childhood (e.g., Kopp, 1989), less research has focused on the dynamic interaction of these two emotion dimensions. Children may display a characteristic pattern of emotionality or reactivity that reflects a central aspect of their temperament or personality. They may also display a particular style of emotion regulation that is adaptive or maladaptive vis-à-vis their individual pattern of reactivity. For example, we suspect that children who have a low threshold of reactivity to novel, mildly stressful stimuli may be buffered from the felt experience of wariness/fearfulness by the degree to which they are soothable. Alternately, children who are highly reactive but unable to be soothed in the presence of moderately arousing stimuli may experience intense feelings of fear and wariness. In short, emotional arousal may facilitate, inhibit, or disrupt behavior; therefore, the adoption of particular regulatory mechanisms may produce a variety of experiences for different individuals (Thompson, 1994). Thus, differences in the synergistic relations between emotion reactivity and regulation may set children on different developmental trajectories to social adaptation or maladaptation.

As aforementioned, studies of emotional reactivity and regulation in early childhood are relatively limited. Much of the extant research is drawn from work regarding the origins of behavioral inhibition (e.g., Kagan, 1989; Kagan, Reznick, Clarke, Snidman, \& Garcia-Coll, 1984; Kagan, Reznick, \& Gibbins, 1989). Recently, for example, Calkins, Fox and Marshall (in press) and Kagan and Snidman (1991) presented data suggesting a relation between early negative emotional reactivity in infancy and the display of inhibited behavior during the second year of life. Behaviorally inhibited toddlers have been found to be more socially wary and reticent than their noninhibited counterparts when interacting with peers at 4 years of age (Calkins, Fox, Rubin, \& Coplan, 1994). These studies suggest that certain patterns of reactivity and regulation may have important consequences for the development of social skills and extrafamilial social relationships during the preschool and school years.

This inference is drawn from reference to the recent writings of Rubin and colleagues (e.g., Rubin \& Mills, 1992; Rubin et al., in press). According to Rubin et al., there may be a developmental pathway by which temperamentally wary/fearful infants who continue to poorly regulate their emotional reactions to novelty during early childhood become socially reticent and socially withdrawn in the peer group. Their initial self-exclusion from their constituency of peers denies these children opportunities to gain the benefits of positive social interaction peer experiences and relationships (for reviews refer to Hartup, 1992; Rubin \& Coplan, 1992); for example, the lack of regular and normal peer experiences renders them socially incompetent (Rubin \& Krasnor, 1986). Furthermore, self-recognition of social incompetence and negative peer relationships engenders feelings and thoughts of negative self-regard (Rubin, 1993). In turn, if left unchecked, negative self-regard brought on by social wariness and anxiety results not only in loneliness, but also depression (Rubin, 1993; Rubin, Hymel, Mills, \& Rose-Krasnor, 1991).

A second developmental pathway described by Rubin and colleagues (Rubin et al., 1991) suggests that dispositionally overactive, fussy, and easily frustrated infants who have difficulty regulating their anger may, under certain conditions (e.g., those requiring frustration tolerance or delay of gratification), become aggressive and hostile in the peer group. Aggression quickly results in peer rejection (e.g., Coie \& Kupersmidt, 1983), which in turn, may preclude the child from experiencing the aforementioned benefits of peer interaction (see also Rubin \& Coplan, 1992, for a discussion). Taken together, it is proposed that these factors result in negative long-term outcomes such as truancy, school drop-out,

Rubin, K.H., Coplan, R.J., Fox, N.A. \& Calkins, S.D. (1995). Emotionality, emotion regulation and preschooler's social adaptation. Development and Psychopathology, 7, 49-62.

Made available courtesy of Cambridge University Press 
and delinquency (see Pepler \& Rubin, 1991 for relevant reviews).

In summary, identifying differences in emotion-regulation strategies that operate to control or manage early emotional reactivity, and constitute the child's behavioral repertoire, may help us isolate the origins of dysregulating behaviors. As noted above, and elsewhere, emotional dysregulation can, given time, contribute to the development of maladaptive behavioral styles that place children at risk for internalizing and/ or externalizing problems (Cole et al., 1994; Garber \& Dodge, 1991; Rubin et al., 1991).

In the investigation described herein, we examined differences in indices of social adaptation and psychopathology as a function of differences in children's emotional reactivity and regulation. The work represents the confluence of research from two laboratories and approaches: (a) the research of Fox and colleagues on temperamental differences in infants and the consequences of these differences for social development (Calkins et al., in press; Fox \& Calkins, 1993), and (b) the research of Rubin and colleagues on the significance of social competence and peer relationships for the development of normalcy and psychopathology (Rubin, Chen, \& Hymel, 1993; Rubin \& Krasnor, 1986). It is generally believed that children who fail to engage, at a normal rate, in competent social interactions (i.e., they engage in predominantly solitary activities as opposed to group activities) will be at risk for later maladaptation, particularly along the internalizing dimension (e.g., see Rubin et al., in press, for a recent review). Similarly, it has been suggested that children who frequently interact with peers, but in a negative fashion, will be at risk for maladaptation, particularly of a externalizing nature (Dishion, Patterson, Stoolmiller, \& Skinner, 1991).

The observational paradigm we developed was designed to assess social interaction (i.e., the degree to which children engage others in group play or conversation), as well as social wariness, task orientation, and impulsivity in a preschool peer group. Drawing from, yet differing somewhat from the theoretical literature extant, we operationalized emotion regulation in terms of the trait constructs of emotionality and soothability. Emotionality represented to us the construct to reactivity-that is, it was operationalized in terms of thresholds and intensity of emotional response. Soothability represented to us the construct of regulation-that is, it was operationalized in terms of recovery (i.e., self-soothing and soothing by contact with others) from an aroused emotional state. Taken together, we identified two groups of children: those who were (a) highly emotional and relatively difficult to soothe (poor affect regulators), and (b) relatively unemotional and relatively easy to soothe (good affect regulators). Because relatively little is known of the interaction between reactivity and regulation, we chose to contrast children who were extremely regulated or dysregulated.

We also identified groups of preschool children on the basis of the degree to which they interacted with unfamiliar peers during free play. It is important to note from the onset, that young children who were highly interactive with unfamiliar agemates are also interactive in more familiar peer contexts (e.g., Asendorpf, in press). Children may engage peers in frequent interaction yet differ, one from another, to the extent that they are competent during interaction. For example, socially competent, popular children, on the one hand, and aggressive children, on the other, may both display relatively high frequencies of interactive activity.

Also, children may refrain from frequent peer interaction yet differ characteristically from one another. For example, although some children may avoid peer interaction because of felt wariness/fearfulness, others may not interact with peers because they are not particularly interested in the peer milieu and instead choose to focus on objects (Asendorpf, 1993).

We posit that both emotion regulation and social interaction are important con-

Rubin, K.H., Coplan, R.J., Fox, N.A. \& Calkins, S.D. (1995). Emotionality, emotion regulation and preschooler's social adaptation. Development and Psychopathology, 7, 49-62.

Made available courtesy of Cambridge University Press 
structs that help determine preschool-aged children's social behavioral patterns. Moreover, we theorize that it is the interaction between emotion regulation and social interaction that may predict the ways that children behave in the company of peers. In short, we do not believe that all "good emotion regulators" are highly interactive, or that all "good emotion regulators" are necessarily socially inhibited. Accordingly, we contrasted five groups of preschoolers: poor affect regulators and low in social interaction; poor affect regulators and high in social interaction; good affect regulators and low in social interaction; good affect regulators and high in social interaction; and a group of children who were moderate social engagers and average in emotion regulation. These latter children represented to us a normal contrast group against which to compare our extreme groups.

Our hypotheses were drawn, in part from the developmental pathways described in our earlier writings (e.g., Rubin et al., 1991; Rubin \& Mills, 1991), in which the child's dispositional characteristics interact with particular behavioral styles to predict adaptive and maladaptive "outcomes." The first set of hypotheses concerned those children who were identified as extremely low in the frequency of social interaction and either as good or poor emotion regulators. We expected that the low social interactors who were also poor affect regulators would be significantly more wary and anxious during peer play and rated as having significantly more internalizing problems by their parents than either the low social interactors/ good regulators or the average children. Alternately, we predicted that the low-frequency social interacting children who were good affect regulators would not differ for the average group in terms of any of the above-mentioned indices of maladaptation. Furthermore we expected that the low social interacting-good regulators, when playing on their own, would be more likely than their low social interacting-poor regulating age-mates, to demonstrate constructive and exploratory activity (solitary- passive play) - a form of solitary play that is viewed as benign and reflective of an object-rather than a person-orientation (Asendorpf, 1993; Coplan \& Rubin, 1993; Rubin, 1982). The low social interacting-poor regulators, on the other hand, were expected to demonstrate significantly more nonsocial reticence (onlooker and unoccupied activity) than the low social interacting-good regulators - a form of solitude reflecting social anxiety and behavioral wariness (Coplan, Rubin, Fox, Calkins, \& Stewart, 1994). These latter findings, if supported, would be in keeping with the perspective that not all forms of nonsocial play are "necessarily evil" (Rubin, 1982).

Our second set of hypotheses concerned children who were identified as high-frequency social interactors and as either good or poor emotion regulators. Generally, children who frequently interact with peers are viewed as being veritable models of social and emotional adaptation. It is noteworthy that in Kagan and colleagues' research (e.g., Kagan, 1989; Kagan \& Snidman, 1991), these highly interactive children are considered uninhibited. We argue herein, however, that highly interactive yet emotionally unregulated preschoolers may be at risk for developing patterns of psychological undercontrol - that is, impulsivity and hostility/aggression. To this end, we hypothesized that children who were frequently involved in social interaction and who were also poor affect regulators would be more disruptive and aggressive, and that they would be rated as having significantly more externalizing problems by their parents, then either extremely interactive children who were good affect regulators or the contrast group of average children. This latter finding, if supported, would suggest that a high frequency of social interaction does not necessarily imply protection from developmental risk.

Finally, we posited that the social inter-actors who were well regulated would perform the most adaptively in a situation of considerable duress-giving an impromptu speech in front of peers.

Rubin, K.H., Coplan, R.J., Fox, N.A. \& Calkins, S.D. (1995). Emotionality, emotion regulation and preschooler's social adaptation. Development and Psychopathology, 7 , 49-62.

Made available courtesy of Cambridge University Press 


\section{Method}

Subjects

The original sample for this study consisted of 96 preschool children (40 males and 56 females) between the ages of 46 and 62 months (mean age $=54.75$ months, $S D=4.8$ months). The children were primarily of middle-class background, living with their families in or near College Park, Maryland. These children were participants in a longitudinal study designed to assess the relations between temperament and social behaviors (e.g., Calkins \& Fox, 1993; Coplan et al., 1994; Fox, 1989). From this original sample, 68 children ( 32 males, 36 females) between the ages of 46 and 62 months were selected according to procedures described below.

\section{Procedures}

Participants were assigned to quartets of unfamiliar same-sex peers whose dates of birth were within 6 months of one another. The children were observed and their behaviors videotaped through a oneway mirror in a small playroom. Each visit consisted of five episodes: unstructured free play (15 min); a clean-up task (5 min); "show-and-tell" speeches (10 min); a ticket-sorting task (10 min); and unstructured free play (15 min).

During the initial free play session, each group of four children was left alone in the play room, where a number of age-appropriate toys was accessible. The children were left undisturbed for the full 15min period. A female research assistant then entered the room and told the children that the play period was over and that it was time to clean up. The children were asked to place all the toys in the room in a large cardboard box.

At the completion of the clean-up, the research assistant asked the children to sit in a circle. Each child was then requested, in turn, to stand up and tell everyone about their last birthday party, "like showand-tell in school." The research assistant encour aged the children to speak; if and when necessary, each child received verbal prompts (e.g., "what else did you do?") during their speeches.

After the speeches, the children were asked to sit at a small table where they were requested to "help out" the researcher by sorting several colored tickets into packets. Each child was asked to make 10 packets, each containing one blue, red, yellow, and green ticket.

After the tickets were sorted (or after $10 \mathrm{~min}$ ), the children were left alone again for a final free play session. The box of toys was brought out, and the children were left undisturbed for $15 \mathrm{~min}$.

Behavioral coding

Free play sessions. Behaviors in the first and second play sessions were coded with Rubin's (1989)

Play Observation Scale. Tens intervals were coded for social participation (unoccupied, onlooking, solitary play, parallel play, conversation, group play) and the cognitive quality of play (functional, dramatic, and constructive play; exploration; games-with-rules). This resulted in approximately 90 coding intervals per child in each of the two free-play sessions.

Additional variables coded during the free-play session included the proportion of observational intervals that included the display of (a) anxious behaviors (e.g., automanipulatives, crying); (b) hovering behavior (remaining inactive, at a distance of less than three feet, for a period of three seconds or more, near where other children are playing); and (c) aggressive behaviors.

Clean-up and ticket-sorting sessions. During the clean-up and ticket-sorting session, the proportion of time each child spent on-task (i.e., actually cleaning up or sorting tickets) was recorded. Two types of unoccupied behaviors also were assessed. Offtask-unoccupied was recorded if the child was offtask, but not engaging in any other activities (i.e., the child was inactive). Time spent off-task but engaged in any other type

Rubin, K.H., Coplan, R.J., Fox, N.A. \& Calkins, S.D. (1995). Emotionality, emotion regulation and preschooler's social adaptation. Development and Psychopathology, 7, 49-62.

Made available courtesy of Cambridge University Press 
of alternative activity (e.g., goofing off, continuing to play with toys, disrupting others who were trying to clean up or sort tickets), was coded as off-task-goofing-off.

Speeches. The speeches were coded for (a) the duration of the entire speech episode, and (b) the percentage of time the child actually spent speaking. The duration of the episode was defined as the amount of time that each child "held the floor," from the moment he/she was asked to speak, until the researcher asked the next child to speak. Each child was asked "Do you have anything else you would like to tell us?" before the next child was requested to speak. The percentage of time spent talking was calculated by dividing the amount of "real" time during which each child verbally described his or her birthday party, by the duration of the speech episode.

Maternal ratings

Mothers completed the Colorado Temperament Inventory (Buss \& Plomin, 1984; Rowe \& Plomin, 1977). This measure comprises factors that assess maternal perceptions of dispositional characteristics (e.g., emotionality, activity level, shyness, soothability). Of specific interest to us were the factors assessing emotionality (five items, e.g., "child often fusses and cries") and soothability (five items, e.g., "when upset by an unexpected situation, child quickly calms down"). Mothers also completed the Child Behavior Checklist (CBCL; Achenbach \& Edelbrock, 1981).

Reliability

The Play Observation Scale (Rubin, 1989) and additional observational variables were coded by four independent observers. Inter-rater reliability on a randomly selected group of children totaling $30 \%$ of the sample (8 quartets; 32 children) was calculated between pairs of observers using Cohen's kappa. For a full variable matrix, including social and cognitive play categories, and additional observational variables, computed

kappas between pairs of raters ranged between $\kappa_{k}=0.71$ and $\kappa_{k}=0.86$. Intercoder disagreements were resolved by review and discussion.

Aggregate variables

Theoretically derived and empirically substantiated aggregate variables were created using various free play and intervening episode variables. The first aggregate variable, representing social wariness, consisted of the sum of the following standardized variables (a) overt demonstrations of anxious behaviors during free play, (b) hovering behavior during free play, and (c) off-taskunoccupied behaviors from both the ticket-sorting and the toy clean-up sessions. Inter-correlations between these four variables ranged from $r=.13$ to $r=.49$, with all but one significant at $p<.05$. The resulting aggregate was then restandardized.

The second aggregate, representing disruptiveness, was created by summing the standardized variables of (a) aggression during free play, and (b) off-task-goofingoff and disruptive behaviors from the toy clean-up and ticket-sorting sessions. Inter-correlations between these three variables ranged from $r=.15$ to $r=.30$, with two of the correlations significant at $p<.05$, and the last at $p<.10$. Finally, an aggregate variable of show-and-tell speech performance was created by combining the standardized variables of (a) speech episode duration; and (b) amount of time spent talking. The correlation between these two variables was $r=.39, p<.001$. The resulting aggregate was then restandardized.

\section{Extreme groups}

To begin with, an aggregate variable was created by first standardizing and then summing the CCTI factors of emotionality and soothability (reversed). A high score on this variable characterized a child who was highly and negatively emotional as well as difficult to soothe. Extreme groups were created by crossing this new variable of negative emotionality-unsoothability (hereaf-

Rubin, K.H., Coplan, R.J., Fox, N.A. \& Calkins, S.D. (1995). Emotionality, emotion regulation and preschooler's social adaptation. Development and Psychopathology, 7, 49-62.

Made available courtesy of Cambridge University Press 
ter referred to as emotion dysregulation) with observed social interaction during free play with peers (instances of group play and peer conversation). It is worth noting that the correlation between observed sociability and emotion dysregulation was nonsignificant $(r=.12)$.

Five groups were created. The first group (low social interaction-good emotion regulators, $n=9$ ) included those children who had (a) social interaction scores in the lowest 33\%, and (b) emotion dysregulation scores in the lowest 33\% of the sample. The second group (low social interaction-poor emotion regulators, $n=10$ ) included those children who had (a) social interaction scores in the lowest $33 \%$, and (b) emotion dysregulation scores in the highest 33\% of the sample. The third group (high social interaction-good emotion regulators, $n=12$ ) included those children who had (a) social interaction scores in the highest 33\%, and (b) emotion dysregulation scores in the lowest $33 \%$ of the sample. The fourth group (high social interaction-poor emotion regulators, $n=8$ ) included those children who had (a) social interaction scores in the highest $33 \%$, and (b) emotion dysregulation scores in the highest $33 \%$ of the sample. The final group (average, $n=29$ ), included those children who had either both (a) social interaction scores in the higher $66 \%$ and (b) emotion dysregulation scores in the middle $33 \%$ of the sample; or children who had both (a) social interaction scores in the middle $33 \%$ and (b) emotion dysregulation scores in the lower $66 \%$ of the sample. ternalizing broadband factor. Results of a one-way ANOVA for behavioral wariness were significant, $F=4.22, p<.05$. Subsequent a priori planned comparisons indicated that, as predicted, the low social interaction-poor emotion regulators $(M=$ 0.76) had significantly higher behavioral wariness scores than both the low social interaction-good emotion regulators $(M=-0.27), t(45)=2.26, p<.05$; and the average group $(M=-0.27), t(45)$ $=2.81, p<.01$. The results are illustrated in Figure 1. Similarly, results from a one-way ANOVA for CBCL internalizing scores were significant $F=3.30, p<.05$. Subsequent a priori planned comparisons indicated that the low social interaction-poor emotion regulators $(M=11.1)$ were rated as having more internalizing problems than both the low social interaction-good emotion regulators $(M$ $=5.5), t(44)=2.37, p<.05$ and the average group $(M=7.1), t(44)=2.17, p<.05$. The results are illustrated in Figure 2.

Next, the two low social interaction groups were compared on the frequencies of different forms of solitary activities during free play. As expected, the results indicated that the low social interactiongood emotion regulators engaged in a significantly higher proportion of solitary-passive behaviors $(M$ $=0.40)$ than reticent behavior $(M=0.18)$ during free play, $t(8)=2.78, p<.05$. For the low social interaction-poor emotion regulators, however, the proportions of these two forms of behaviors did not differ significantly $(M$ reticent $=0.26, M$ solitary-passive $=0.31)$.

Results

Low social interaction-good emotion regulators versus low social engagement-poor emotion regulators

The first series of analyses concerned group differences between the low social interaction-good emotion regulators, the low social interaction-poor emotion regulators, and the average group vis-à-vis the behavioral wariness aggregate and the CBCL in-

High social interaction-good emotion regulators versus high social interaction-poor emotion regulators

Next, we examined group differences between the high social interaction-good emotion regulators, the high social interaction-poor emotion regulators, and the average group in terms of behavioral disruptiveness and CBCL externalizing scores. A one-way ANOVA for behavioral disruptiveness was nonsignificant, $F=1.56$, NS. Subsequent

Rubin, K.H., Coplan, R.J., Fox, N.A. \& Calkins, S.D. (1995). Emotionality, emotion regulation and preschooler's social adaptation. Development and Psychopathology, 7, 49-62.

Made available courtesy of Cambridge University Press 


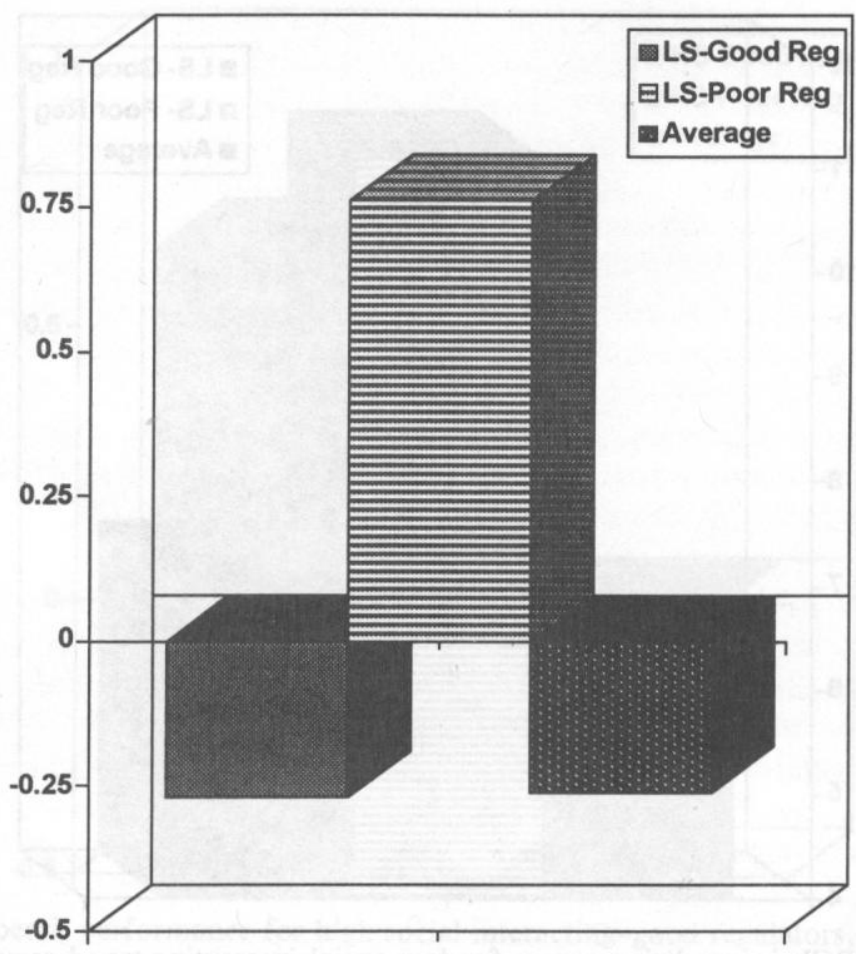

Figure 1. Aggregate wariness scores for low social interacting-good regulators, low social interacting-poor regulators, and average group.

a priori planned comparisons indicated that the high social interaction-poor emotion regulators $(M=$ $0.36)$, high social interaction-good emotion regulators $(M=0.05)$ and the average group $(M=-0.14)$ did not differ significantly from each other in terms of observed disruptiveness. Results from a one-way ANOVA on CBCL externalizing scores, however, did yield statistical significance, $F=3.22, p<.05$. Subsequent a priori planned comparisons indicated, as expected, that the high social interaction-poor emotion regulators were rated as having more externalizing problems $(M=11.3)$ than both the high social interaction-good emotion regulators $(M=5.2)$ and the average group $(M=7.5), t(45) \mathrm{s}=$ $2.54, p<.05$ and 1.77, $p<.10$, respectively. The results are illustrated in Figure 3.

The final set of analyses compared the speech performances of the high social interaction-good emotion regulators, the high social interaction-poor emotion regu lators, and the average group. Although a oneway ANOVA failed to yield significant findings, $F=2.20$, NS, results from a priori planned comparisons indicated that the high social interaction-good emotion regulators $(M=0.65)$ demonstrated better speech performance than the average group $(M=-0.01), t(46) 1.60, p<.05$. The findings are shown in Figure 4.

Discussion

The central thesis in this study was that emotion dysregulation may be a significant source of dysfunctional socioemotional development. This notion is clearly in keeping with contemporary perspectives on the dispositional underpinnings of psychopathology in childhood (e.g., Dodge, 1991). However, the development of psychopathology is a complex phenomenon that cannot be explained merely by focusing on emotion regulation difficulties. To this end, we spec-

Rubin, K.H., Coplan, R.J., Fox, N.A. \& Calkins, S.D. (1995). Emotionality, emotion regulation and preschooler's social adaptation. Development and Psychopathology, 7, 49-62.

Made available courtesy of Cambridge University Press 


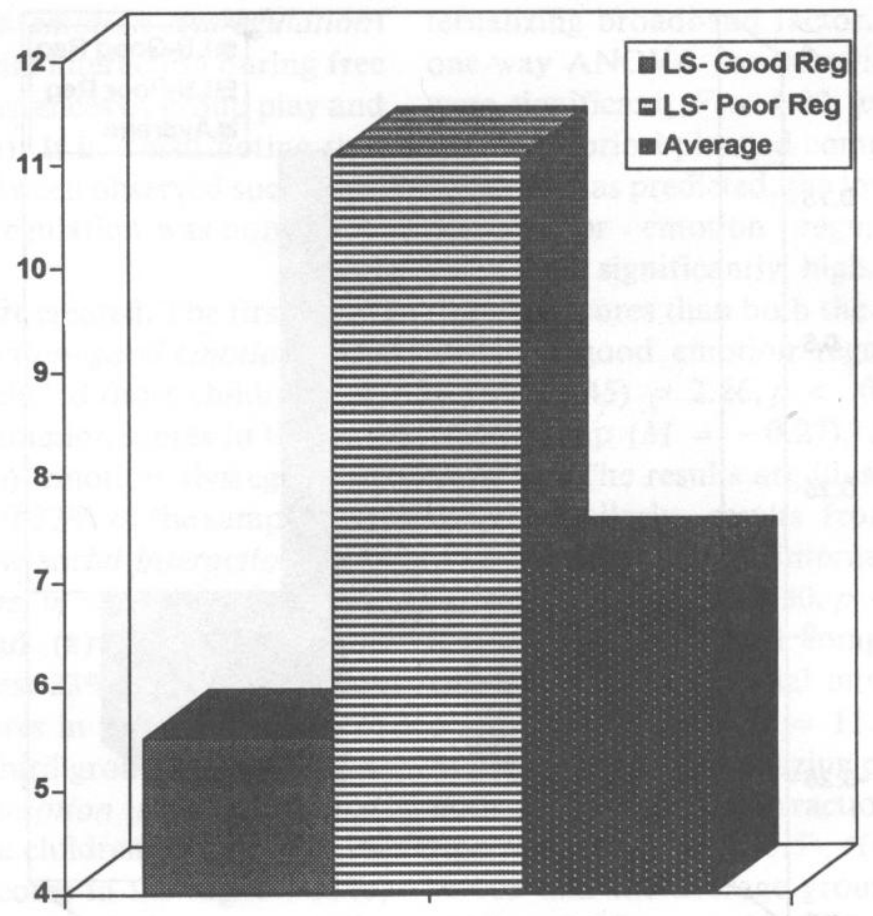

Figure 2. $\mathrm{CBCL}$ internalizing scores for low social interacting-good regulators, low social interacting-poor regulators, and average group.

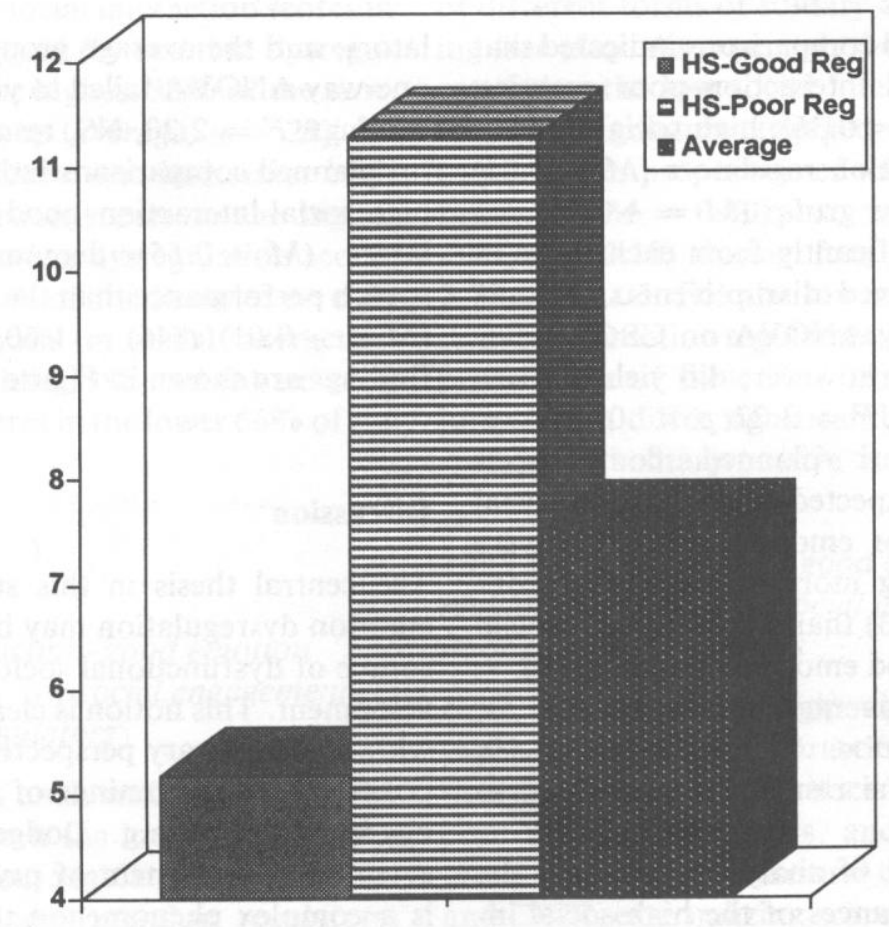

Figure 3. $\mathrm{CBCL}$ externalizing scores for high social interacting-good regulators, high social interacting-poor regulators, and average group.

Rubin, K.H., Coplan, R.J., Fox, N.A. \& Calkins, S.D. (1995). Emotionality, emotion regulation and preschooler's social adaptation. Development and Psychopathology, 7, 49-62.

Made available courtesy of Cambridge University Press 


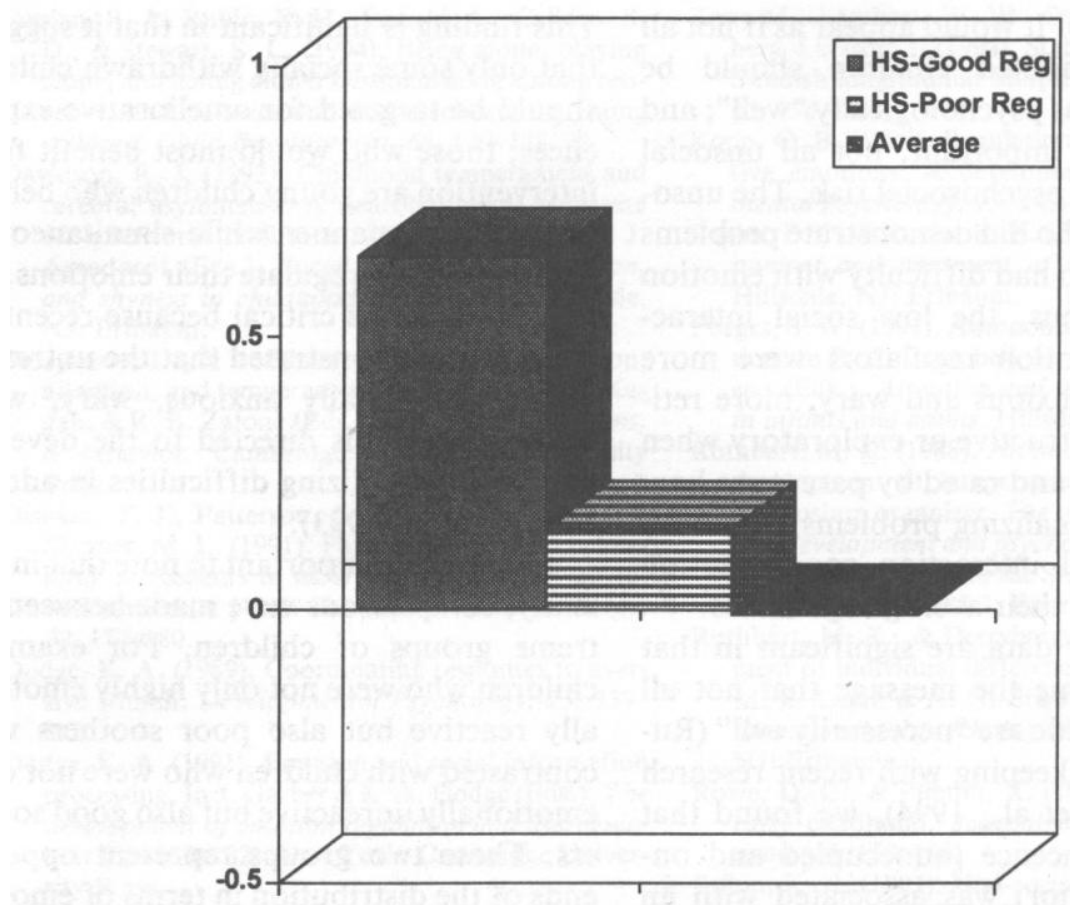

Figure 4. Speech performance for high social interacting-good regulators, high social interacting-poor regulators, and average group.

ulated that children's behavioral tendencies, in concert with behavioral and emotional control, would provide a more detailed window into the understanding and prognosis of socioemotional disorder.

Thus, we have argued that the "costs" of emotion dysregulation vary in accord with the child's behavioral tendency to approach and interact with peers during free play. For example, in the face of claims that American parents, "reflecting the values of their society, regard bold, spontaneous, social behavior as more adaptive than shyness and timidity" (Kagan, Gibbins, Johnson, Reznick , \& Snidman, 1990, p. 171), our research demonstrates that highly social interactive young children do not necessarily follow a fixed developmental pathway to socioemotional adaptation. Socially interactive children whose approach behaviors lack regulatory control may be "at risk" for developing psychological difficulties of an externalizing nature (see also Dodge, 1991). On the other hand, highly nonsocially interactive children are not necessarily on a pre ordained developmental pathway to maladaptation; the ability to regulate affect may serve as a protective factor displacing them from a potentially problematic trajectory.

These latter messages were clearly supported in this study. Children who were high in social interaction but poor emotion regulators were rated by their parents as having externalizing problems and they were $0.36 S D$ above the mean on an observational measure of disruptiveness. Children who were low in social interaction but good emotion regulators appeared to suffer no ill effects of their lack of social behavior. When playing alone, they were productive engagers in constructive and exploratory activity. They did not display anxious behaviors in the peer group, and they were not rated by parents as having socioemotional difficulties of any sort.

These data are particularly relevant for those who have been studying behavioral inhibition in childhood (e.g., Broberg, 1993; Davidson, 1993; Kagan et al., 1990; Kerr, Lambert, Stattin, \& Klackenberg-

Rubin, K.H., Coplan, R.J., Fox, N.A. \& Calkins, S.D. (1995). Emotionality, emotion regulation and preschooler's social adaptation. Development and Psychopathology, 7, 49-62.

Made available courtesy of Cambridge University Press 
Larsson, 1994). It would appear as if not all socially uninhibited children should be characterized as psychologically "well"; and perhaps more important, not all unsocial children are at psychosocial risk. The unsocial children who did demonstrate problems were those who had difficulty with emotion regulation. Thus, the low social interaction-poor emotion regulators were more behaviorally anxious and wary, more reticent than constructive or exploratory when playing alone, and rated by parents as having more internalizing problems than both the low social interaction-good emotion regulators and their average age-mates.

These latter data are significant in that they drive home the message that not all forms of solitude are "necessarily evil" (Rubin, 1982). In keeping with recent research (e.g., Coplan et al., 1994), we found that behavioral reticence (unoccupied and onlooking behavior) was associated with an unsocial, emotional dysregulation profile, and solitary-passive play (solitary exploration an construction) was associated with an unsocial, emotional regulation profile.

This finding is significant in that it suggests that only some socially withdrawn children should be targeted for ameliorative experiences; those who would most benefit from intervention are young children who behave in a reticent manner while simultaneously being unable to regulate their emotions. Intervention seems critical because recent research has demonstrated that the untreated course for socially anxious, wary, withdrawn children is directed to the development of internalizing difficulties in adolescence (Rubin, 1993).

Finally, it is important to note that in this study, comparisons were made between extreme groups of children. For example, children who were not only highly emotionally reactive but also poor soothers were contrasted with children who were not only emotionally unreactive but also good soothers. These two groups represent opposite ends of the distribution in terms of emotion dysregulation. Clearly, future research is required to investigate how emotionality and soothability interact to produce adaptive and maladaptive "outcomes."

\section{References}

Achenbach, T. M., \& Edelbrock, C. S. (1981). Behavioral problems and competencies reported by parents of normal and disturbed children aged four through sixteen. Monographs of the Society for Research in Child Development, 46, (1, Serial No. 188).

Asendorpf, J. B. (1993). Beyond temperament: A two factorial coping model of the development of inhibition during childhood. In K. H. Rubin \& J. Asendorpf (Eds.), Social withdrawal, inhibition, and shyness in childhood (pp. 265-289). Hillsdale, NJ: Erlbaum.

Asendorpf, J. B. (in press). Social and personality development. In F. Weinert (Ed.), The Munich Longitudinal Study on the Genesis of Individual Competencies (LOGIC). Hillsdale, NJ: Erlbaum.

Belsky, J., \& Rovine, M. (1987). Temperament and attachment security in the Strange Situation: An empirical rapprochement. Child Development, 58, 787-795.

Broberg, A. G. (1993). Inhibitions and children's experiences of out-of-home care. In K. H. Rubin \& J. Asendorpf (Eds.), Social withdrawal, inhibition, and shyness in childhood (pp. 151-176). Hillsdale, NJ: Erlbaum.

Buss, A. H., \& Plomin, R. (1984). Temperament: Early developing personality traits. Hillsdale, NJ: Erlbaum.

Calkins, S., \& Fox, N. (1992). The relations between infant temperament, security of attachment and behavioral inhibition at 24 months. Child Development, 63, 1456-1472.

Calkins, S. D., Fox, N. A., \& Marshall, T. R. (in press). Behavioral and physiological correlates of inhibition in infancy. Child Development.

Calkins, S. D., Fox, N. A., Rubin, K. H., \& Coplan, R. J. (in preparation). Longitudinal outcomes of behavioral inhibition: Implications for behavior in a peer setting.

Campos, J. J., Campos, R. G., \& Barrett, K. C. (1989). Emergent themes in the study of emotional development and emotion regulation. Developmental Psychology, 25, 394-402.

Cole, P., Michel, M. K., \& O'Donnell, L. (1994). The development of emotional regulation and dysregulation. In N. A. Fox (Ed.), The development of emotion regulation: Biological and behavioral considerations. Monographs of the Society for Research in Child Development (pp. 73-100). Chicago: University of Chicago Press.

Coplan, R. J., \& Rubin, K. H. (1993). Multiple forms of social withdrawal in young children: Reticence and solitary-passive behaviors. Paper presented at the Biennial Meetings of the International Society for the Study of Behavioral Development. Recife, Brazil.

Coplan, R. J., Rubin, K. H., Fox, N. A., Calkins, S. D., \& Stewart, S. L. (1994). Being alone, playing alone, and acting alone: Distinguishing among reticence, and passive- and active-solitude in young children. Child Development, 65, 129-138.

Rubin, K.H., Coplan, R.J., Fox, N.A. \& Calkins, S.D. (1995). Emotionality, emotion regulation and preschooler's social adaptation. Development and Psychopathology, 7 , 49-62.

Made available courtesy of Cambridge University Press 
Davidson, R. J. (1993). Childhood temperament and cerebral asymmetry: A neurobiological substrate of behavioral inhibition. In K. H. Rubin \& J. Asendorpf (Eds.), Social withdrawal, inhibition, and shyness in childhood (pp. 31-48). Hillsdale, NJ: Erlbaum.

Derryberry, D., \& Rothbart, M. K. (1984). Emotion, attention, and temperament. In C. E. Izard, J. Kagan, \& R. B. Zajonc (Eds.), Emotions, cognitions, \& behavior. Cambridge: Cambridge University Press.

Dishion, T. J., Patterson, G. R., Stoolmiller, M., \& Skinner, M. L. (1991). Family, school, and behavioral antecedents to early adolescent involvement with antisocial peers. Developmental Psychology, 27, 172-180.

Dodge, K. A. (1989). Coordinating responses to aversive stimuli. Developmental Psychology, 25, 339342.

Dodge, K. A. (1991). Emotion and social information processing. In J. Garber \& K. A. Dodge (Eds.), The development of emotion regulation and dysregulalion (pp. 159-182). New York: Cambridge University Press.

Fox, N. A., \& Calkins, S. D. (1993). Pathways to aggression and social withdrawal: Interactions among temperament, attachment, and regulation. In K. Rubin \& J. Asendorpf (Eds.), Social withdrawal, inhibition, and shyness in childhood. Hillsdale, NJ: Erlbaum.

Garber, J., Braafladt, N., \& Zeman, J. (1991). The regulation of sad affect: An information processing perspective. In J. Garber $\&$ K. A. Dodge (Eds.), The development of emotion regulation and dysregulation (pp. 208-242). New York: Cambridge University Press.

Garber, J., \& Dodge, K. A. (Eds.). (1991). The development of emotion regulation and dysregulation. New York: Cambridge University Press.

Hartup, W. W. (1992). Peer relations in early and middle childhood. In V. B. Van Hasset \& M. Hersen (Eds.), Handbook of social development (pp. 257281). New York: Plenum Press.

Kagan, J. (1989). Temperamental contributions to social behavior. American Psychologist, Vol. 44(4), 668-674.

Kagan, J., Gibbons, J. L., Johnson, M. 0., Reznick, J. S., \& Snidman, N. (1990). A temperamental disposition to the state of uncertainty. In J. Rolf, A. S. Masten, D. Cicchetti, K. H. Nuechterlein, \& S. Weintraub (Eds.), Risk and protective factors in the development of psychopathology (pp. 164178). New York: Cambridge University Press.

Kagan, J., \& Snidman, N. (1991). Infant predictors of inhibited and uninhibited profiles. Psychological Science, 2, 40-44.

Kagan, J., Reznick, J. S., Clarke, C., Snidman, N., \& Garcia-Coll, C. (1984). Behavioral inhibition to the unfamiliar. Child Development, $55,22122225$.

Kagan, J., Reznick, J. S., \& Gibbons, J. (1989). Inhibited and uninhibited types of children. Child Development, 60, 838-845.

Kerr, M., Lambert, W. W., Stattin, H., \& Klackenberg-Larsson, I. (1994). Stability of inhibition in a Swedish longitudinal sample. Child Development, 65, 138-146.

Kopp, C. B. (1989). Regulation and distress of negative emotions: A developmental view. Developmental Psychology, 25, 343354.

Pepler, D. J., \& Rubin, K. H. (Eds.) (1991). The development and treatment of childhood aggression. Hillsdale, NJ: Erlbaum.

Porges, S. W. (1991). Autonomic regulation and attention. In B. A. Campbell, H. Hayne, \& R. Richardson (Eds.), Attention and information processing in infants and adults. Hillsdale, NJ: Erlbaum.

Rothbart, M. K. (1988). Attention and emotion in the development of temperament. In M. I. Posner, symposium organizer, The role of attention in normal development and psychopathology. University of Oregon, Center for the Study of Emotion (Technical Report No. 88-3, Eugene, OR).

Rothbart, M. K., \& Derryberry, D. (1981). Development of individual differences in temperament. In M. E. Lamb \& A. N. Brown (Eds.), Advances in developmental psychology (pp. 38-85). Hillsdale, NJ: Erlbaum.

Rowe, D. C., \& Plomin, R. (1977). Temperament in early childhood. Journal of Personality Assessment, 41, 150-156. Rubin, K. H. (1982). Non-social play in preschoolers: Necessary evil? Child Development, 53, 651-657.

Rubin, K. H. (1989). The play observation scale (POS). University of Waterloo.

Rubin, K. H. (1993). The Waterloo Longitudinal Project: Correlates and consequences of social withdrawal from childhood to adolescence. In K. H. Rubin \& J. Asendorpf (Eds.), Social withdrawal, inhibition, and shyness in childhood (pp. 291-314). Hillsdale, NJ: Erlbaum.

Rubin, K. H., Chen, X., \& Hymel, S. (1993). Socioemotional characteristics of aggressive and withdrawn children. MerrillPalmer Quarterly, 49, 518-534.

Rubin, K. H., \& Coplan, R. J. (1992). Peer relationships in childhood. In M. Bornstein \& M. Lamb (Eds.), Developmental psychology: An advanced textbook (pp. 519-578). Hillsdale, NJ: Erlbaum.

Rubin, K. H., Hymel, S., Mills, R. S. L., \& Rose-Krasnor, L. (1991). Conceptualizing different pathways to and from social isolation in childhood. In D. Cicchetti \& S. Toth (Eds.), The Rochester symposium on developmental psychopathology, Vol. 2, Internalizing and externalizing expressions of dysfunction (pp. 91-122). New York: Cambridge University Press.

Rubin, K. H., \& Krasnor, L. R. (1986). Social-cognitive and social behavioral perspectives on problem solving. In M. Perlmutter (Ed.), Cognitive perspectives on children's social and behavioral development (Vol. 18, pp. 1-68). The Minnesota Symposia on Child Psychology. Hillsdale, NJ: Erlbaum.

Rubin, K. H., \& Mills, R. S. L. (1991). Conceptualizing developmental pathways to internalizing disorders in childhood. Canadian Journal of Behavioural Science, 23, 300-317.

Rubin, K. H., Stewart, S. L., \& Coplan, R. J. (in press). Social withdrawal in childhood: Conceptual and empirical perspectives. In T. 011endick \& R.

Rubin, K.H., Coplan, R.J., Fox, N.A. \& Calkins, S.D. (1995). Emotionality, emotion regulation and preschooler's social adaptation. Development and Psychopathology, 7, 49-62.

Made available courtesy of Cambridge University Press 
Prinz (Eds.), Advances in clinical child psychology, Vol. 17. New York: Plenum Press.

Stifter, C. A., \& Fox, N. A. (1990). Infant reactivity and regulation: Physiological correlates of newborn and five month temperament. Developmental Psychology, 26, 582-588.

Thompson, R. A. (1990). Emotion and self-regulation. In R. A. Thompson (Ed.), Socioemotional development: Nebraska symposium on motivation (Vol.

36, pp. 367-467). Lincoln, NE: University of Nebraska Press.

Thompson, R. A. (1994). Emotion regulation: A theme in search of a definition. In N. A. Fox (Ed.), The development of emotion regulation: Biological and behavioral considerations. Monographs of the Society for Research in Child De-

velopment (pp. 25-52). Chicago: University of Chicago Press.

Rubin, K.H., Coplan, R.J., Fox, N.A. \& Calkins, S.D. (1995). Emotionality, emotion regulation and preschooler's social adaptation. Development and Psychopathology, 7, 49-62.

Made available courtesy of Cambridge University Press 